\title{
Uptake of permanganate from aqueous environment by surfactant modified montmorillonite batch and fixed bed studies
}

\author{
N MAHADEVAIAH*, B VIJAYAKUMAR ${ }^{\dagger}$, K HEMALATHA ${ }^{\dagger \dagger}$ and B S JAI PRAKASH ${ }^{\#}$ \\ Solid State and Structural Chemistry Unit, Indian Institute of Science, Bangalore 560 012, India \\ ${ }^{\dagger}$ Department of Chemistry, Indian Institute of Technology Madras, Chennai 600 036, India \\ ${ }^{\dagger}$ Department of Chemistry, Vemana Institute of Technology, Bangalore 560 034, India \\ \#Bangalore Institute of Technology, Bangalore 560 004, India
}

MS received 8 March 2010; revised 23 September 2010

\begin{abstract}
Organo-clay was prepared by incorporating different amounts (in terms of CEC, ranging from $134-840 \mathrm{mg}$ of quaternary ammonium cation (QACs) such as hexadecytrimethylammonium bromide $\left(\left[\mathrm{C}_{19} \mathrm{H}_{42} \mathrm{~N}\right] \mathrm{Br}\right)$ into the montmorillonite clay. Prepared organo-clays are characterized by $\mathrm{CHN}$ analyser and XRD to measure the amount of elemental content and interlayer spacing of surfactant modified clay. The batch experiments of sorption of permanganate from aqueous media by organo-clays was studied at different acidic strengths (pH 1-7). The experimental results show that the rate and amount of adsorption of permanganate was higher at lower $\mathrm{pH}$ compared to raw montmorillonite. Laboratory fixed bed experiments were conducted to evaluate the breakthrough time and nature of breakthrough curves. The shape of the breakthrough curves shows that the initial cationic surfactant loadings at 1.0 CEC of the clay is enough to enter the permanganate ions in to the interlamellar region of the surfactant modified smectile clays. These fixed bed studies were also applied to quantify the effect of bed-depth and breakthrough time during the uptake of permanganate. Calculation of thermodynamic parameters shows that the sorption of permanganate is spontaneous and follows the first order kinetics.
\end{abstract}

Keywords. Organo-clays; permanganate adsorption; surfactants; breakthrough curve; breakthrough time; column studies.

\section{Introduction}

Manganese is one of the most abundant metals on the earth's surface. Manganese is not found naturally in its pure (elemental) form, but is a component of over several minerals (ATSDR 2000). It is an essential micronutrient for organisms and plants at low doses (Keen et al 2000). Manganese compounds may be present in the atmosphere as suspended particulates resulting from industrial emissions, soil erosion, volcanic emissions, manganese containing pesticides and the burning of methylcyclopentadienyl manganese tricarbonyl (MMT) containing gasoline (Donavan et al 1999; IPCS 1999). The major resource of entering of manganese into the water system are manufacturer of iron and steel alloy, manganese dioxide and other manganese compounds are used in products such as dry-cell batteries, glass, fireworks, welding industries, automobile and gasoline production (Griffin 1960; IPCS 1999; ATSDR 2000). In general, the concentration of manganese in natural waters is in the range 0.02$130 \mu \mathrm{g} / \mathrm{l}$. But concentrations of manganese exceeding

\footnotetext{
*Author for correspondence (devnmahadev@ gmail.com)
}

$0 \cdot 1 \mathrm{mg} / \mathrm{l}$ in water bodies reduces the biological oxygen demand of water in pools, imports undesirable taste and affects the central nervous system to the living bodies (Tucker and Boyd 1977; Bown 1979; Boyd 1990; Zhang et al 1997).

The untreated effluents from such sources pollute the water system because of the harmful effects of manganese species (Lin and Juang 2002). Wastewater and industrial effluents containing this element must be treated before discharging to water bodies (Boyd 1990). Among many adsorbents that are available for the removal of such toxicants from water systems, there is a search for eco-friendly and cheaper ones such as clays.

Clays are smectic in nature and possess a net negative charge resulting from isomorphic substitution of cations in the crystal lattice. Montmorillonite is a kind of $2: 1$ type layered clay minerals and has been widely used in various branches of industry due to their high cation exchange capacity, swelling ability and high surface area. The hydrophilic surface of montmorillonite can be changed to hydrophobic by replacement of interlayer hydrated cations with various organocations. These modified minerals, organo-clays, represent a family of materials which have a lot of applications in a range of key 
areas, such as ion-exchange materials, adsorbents, catalysts, modified electrodes, and inorganic/organic composite materials adsorbents for inorganic/organic pollutants, rheological control agents and reinforcing fillers for plastics (Patchett and Tatsumoto 1975; Lin and Juang 2002; Krishna et al 2004).

The surface modifications with organic cations have been widely used in order to alter the surface properties of swelling clays to improve their adsorption ability (Mahadevaiah et al 2008). Quaternary ammonium salts such as hexadecyltrimethylammonium (HDTMA) bromides are known to swell smectite layers to different extents depending on their initial loading. Surfactant immobilized interlayer species (SIIS) bound to clay can facilitate the admission of cations and anions into the interlayer of the clay (Mahadevaiah et al 2007).

In the present work, fixed bed adsorption studies were performed on surfactant modified montmorillonite clay to retain and recover permanganate. The objective was to achieve adsorption of aqueous permanganate into the clay interlayer by loading different amounts of surfactant to the smectite.

\section{Experimental}

\subsection{Materials}

The clay mineral used in this study was swelling type smectite-rich clay from the Bhuj area of Gujarat, India. The sample, having a mesh size of $<75 \mu \mathrm{m}$, was essentially montmorillonite as characterized by X-ray diffraction and X-ray fluorescence spectrometry. The BET surface area was measured with a sorptiometer (Quantachrome Nova 1000) and was found to be $14.2 \mathrm{~m}^{2} \mathrm{~g}^{-1}$ from the nitrogen adsorption isotherms. The cation exchange capacity (CEC) of montmorillonite was $0.92 \mathrm{meq} \mathrm{g}^{-1}$ of the clay. The surfactant used in this study for modification of surface of the clay was hexadecyltrimethylammonium (HDTMA) bromide. Potassium permanganate is purchased from SD Fine chemicals, India. Distilled water was used to prepare aqueous solutions for tests in this study. The variation of $\mathrm{pH}$ of resultant solution was adjusted by using $0.5 \mathrm{~N} \mathrm{HCl}$ and ammonia solution.

\subsection{Preparation of surfactant modified smectite clay}

The modification of clay was carried out as discussed elsewhere (Krishna et al 2004). It consist of dissolved $10 \mathrm{mmol}$ of hexadecyltrimethylammonium bromide in 11 of distilled water. $100 \mathrm{~g}$ of montmorillonite clay suspension in acetone was added to HDTMA solution. Acetone was used to make the clay suspension less sticky and easier to handle. The contents were shaken using a mechanical shaker for $1 \mathrm{~h}$. The mixture was centrifuged and the centrifugate was discarded. The solid was washed several times with milli pore water to remove superficially held adsorbate. The resulting modified clay was ground, sieved and finally dried at $105^{\circ} \mathrm{C}$ in a hot air oven. The amount of surfactant (HDTMA) adsorbed was determined by carbon-hydrogen analysis using a Carlo Erba CHNanalyser instrument.

\subsection{Characterization of surfactant modified smectite clay}

The XRD patterns of surfactant modified smectite samples were investigated with a Siemens D 5000 diffractometer (Curved Germanium 111 monochromator, $1 \mathrm{~mm}$ soller slits, a $0.6 \mathrm{~mm}$ receiving slit, $\mathrm{CuK} \alpha$ radiation). The samples were applied on a glass sample holder, and then passed over several times with a glass slide in an attempt to achieve proper texture. The samples were analysed on a Si (001) sample holder. Diffractograms were recorded from $2 \theta=2^{\circ}-40^{\circ}$ in steps of $0.04^{\circ}$ with $15 \mathrm{~s}$ counting time for each step.

Amount of carbon, hydrogen and nitrogen content present in the surfactant modified smectite clay was analysed using Leco CHN-600 analyser by burning tin capsules at $1800^{\circ} \mathrm{C}$ in pure oxygen, resulting in production of $\mathrm{CO}_{2}$, $\mathrm{H}_{2} \mathrm{O}$ and $\mathrm{N}_{2}$.

\subsection{Adsorption of permanganate (batch experiments)}

To the above prepared surfactant modified smectite (HDTMA-clay), a known amount of potassium permanganate was added and the mixture was periodically shaken for $45 \mathrm{~min}$ and then centrifuged at 10,000 rpm for $5 \mathrm{~min}$. The amount of permanganate present in the centrifugate was analysed volumetrically using oxalic acid method (Sandell 1958). The difference in the values was taken as the amount of permanganate adsorbed.

\subsection{Column experiments}

A known dried weight (16 g) of HDTMA modified smectite was packed into a glass column with an inside diameter of $3 \mathrm{~cm}$ and height of $30 \mathrm{~cm}$. The data in table 1 show physicochemical characteristics of column and bed. Deionized water was used to wash the sorbent in a down flow fashion in order to rinse the adsorbent and equilibrate the particles in the column before a column test was begun. Permanganate solution of known concentration $(3.52 \mathrm{mg} / \mathrm{ml})$ was allowed to flow from a reservoir through the glass column with a control valve. The permanganate solution ( $\mathrm{pH}$ adjusted) was continuously fed to the top of the column at a desired flow rate controlled by a suction pump. The column effluent was intermittently collected in a separate collector and the effluent concentration was measured volumetrically (Sandell 1958) until a breakthrough occurred and the concentration of permanganate in the effluent remained constant. 
Table 1. Physicochemical characteristics of column and bed.

\begin{tabular}{lcccc}
\hline & \multicolumn{4}{c}{ Surfactant loaded (CEC) } \\
\cline { 2 - 5 } Physical characteristics of column material & $0 \cdot 5$ & $1 \cdot 0$ & $1 \cdot 5$ & $2 \cdot 0$ \\
\hline Weight of sorbent $(\mathrm{g})$ & $12 \cdot 01$ & $12 \cdot 0$ & $12 \cdot 0$ & $12 \cdot 0$ \\
Density of adsorbent $(\mathrm{g} / \mathrm{ml})$ & $1 \cdot 07$ & $1 \cdot 08$ & $1 \cdot 09$ & $1 \cdot 09$ \\
Column diameter $(\mathrm{cm})$ & $3 \cdot 0$ & $3 \cdot 0$ & $3 \cdot 0$ & $3 \cdot 0$ \\
pH of permanganate solution $( \pm 0 \cdot 1)$ & $1 \cdot 5$ & $1 \cdot 5$ & $1 \cdot 5$ & $1 \cdot 5$ \\
Concentration of permanganate $(\mathrm{mg} / \mathrm{ml})$ & $3 \cdot 5$ & $3 \cdot 5$ & $3 \cdot 5$ & $3 \cdot 5$ \\
Column bed height $(\mathrm{cm})$ & $2 \cdot 5$ & $2 \cdot 5$ & $2 \cdot 5$ & $2 \cdot 5$ \\
Flow rate $( \pm 0 \cdot 2 \mathrm{ml} / \mathrm{min})$ & $3 \cdot 5$ & $3 \cdot 5$ & $3 \cdot 5$ & $3 \cdot 5$ \\
\hline
\end{tabular}
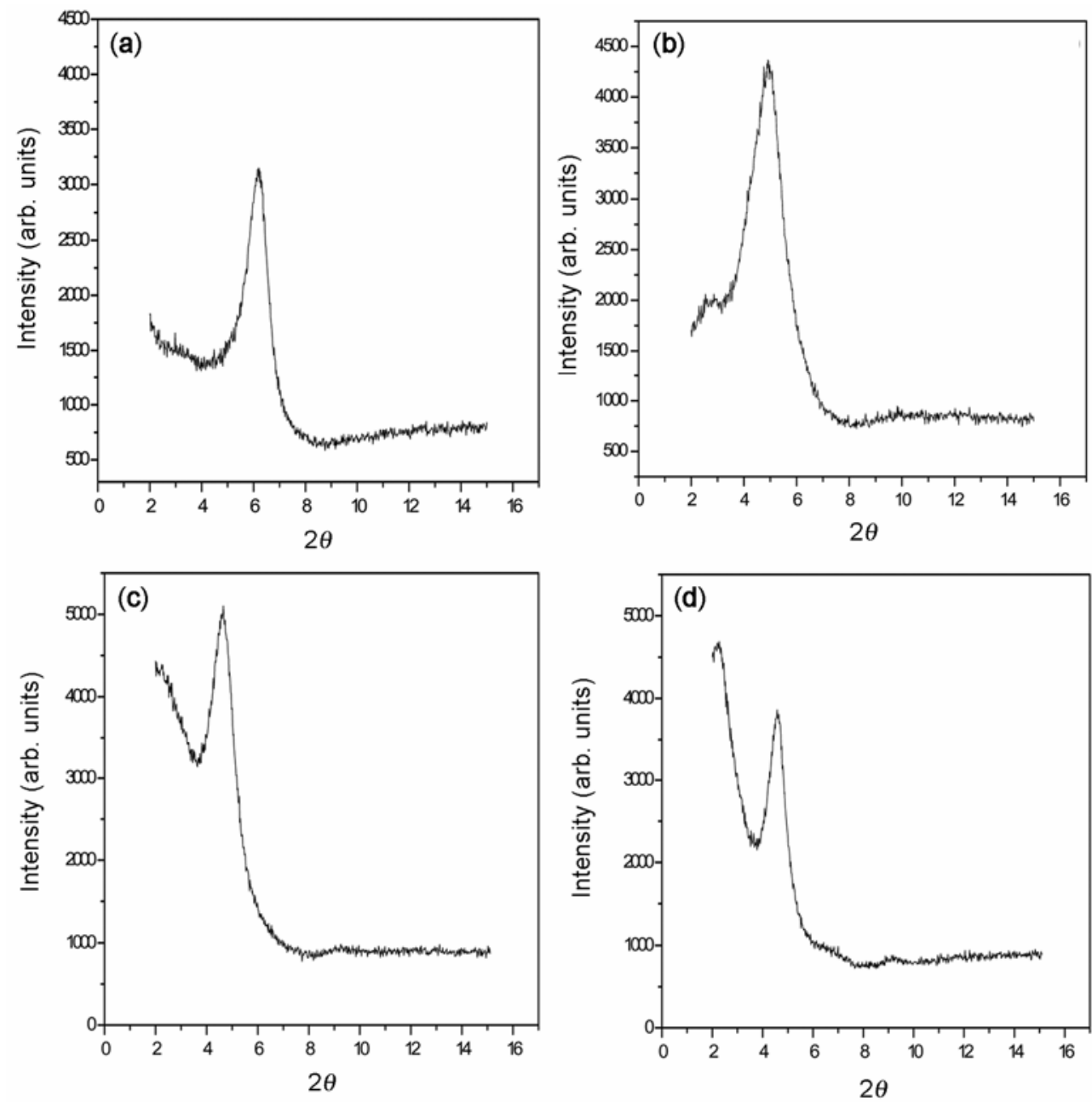

Figure 1. XRD patterns of (a) $0.5 \mathrm{CEC},(\mathbf{b}) 1.0 \mathrm{CEC},(\mathbf{c}) 1.5 \mathrm{CEC}$ and (d) $2.0 \mathrm{CEC}$ HDTMA loaded clays.

The time, $t$, was taken as 10 min when flow of the desired permanganate just appeared in the column effluent.

\section{Results and discussion}

\subsection{XRD analysis}

HDTMA was adsorbed by cation exchange with the releasing of an equivalent amount of inorganic cations.
Figure 1 shows powder X-ray diffraction (XRD) patterns of the clay material resulting from intercalation of quaternary ammonium cation such as HDTMA showing a clear swelling of the interlayers. The data in table 2 show the increased interlayer spacings. The interlayer spacing of the clay without modification was found to be $9.5 \AA$ but after modification interlayer distance was increased up to $40 \cdot 5 \AA$ for 2 CEC surfactant loaded clay.

The basal spacing determined by X-ray powder diffraction indicates that the HDTMA adsorbed between the 
interlaminar gaps of the clay since the $d_{001}$ spacing of the precursor montmorillonite is lower than those of the surfactant modified forms. It corresponds to the shifting of $d_{001}$ peak of most of the modified samples to lower diffraction angles or lower $2 \theta$ values, than that of the montmorillonite. The initial loading of HDTMA affects the interlayer spacing in the order $0.5 \mathrm{CEC}$-clays $<1.0 \mathrm{CEC}$ clays $<1.5$ CEC-clays $<2.0$ CEC-clays.

\subsection{CHN analysis}

The data in table 3 show that the amount of HDTMA sorbed between the montmorillonite layers at different initial surfactant loadings with respect to CEC was measured by $\mathrm{CHN}$ anlayser. At higher loadings of HDTMA, the modified clay was found to retain increased amounts of HDTMA. The sample treated with an initial loading of surfactant equivalent to 1.0 CEC is found to retain almost all the added HDTMA, whereas those loaded initially with 1.5 and 2.0 CEC showed more retention than CEC. Above 2.0 CEC initial loading, there was no increase in the amount of HDTMA retained.

\section{3 pH studies}

Figure 2 shows $\mathrm{pH}$ dependence of permanganate sorption on surfactant modified montmorillonite clays which

Table 2. Basal spacings $\left(d_{001}\right)$ of surfactant treated clays.

\begin{tabular}{lc}
\hline $\begin{array}{l}\text { Initial surfactant } \\
\text { loading (CEC) }\end{array}$ & $\begin{array}{c}\text { Basal spacing of } \\
\text { HDTMA clay }(\AA)\end{array}$ \\
\hline 0.5 & $14 \cdot 5$ \\
$1 \cdot 0$ & $18 \cdot 2$ \\
1.5 & $32 \cdot 6$ \\
$2 \cdot 0$ & $40 \cdot 5$ \\
& $9 \cdot 5^{*}$ \\
\hline
\end{tabular}

*Raw montmorillonite clay (dried at $110^{\circ} \mathrm{C}$ ).

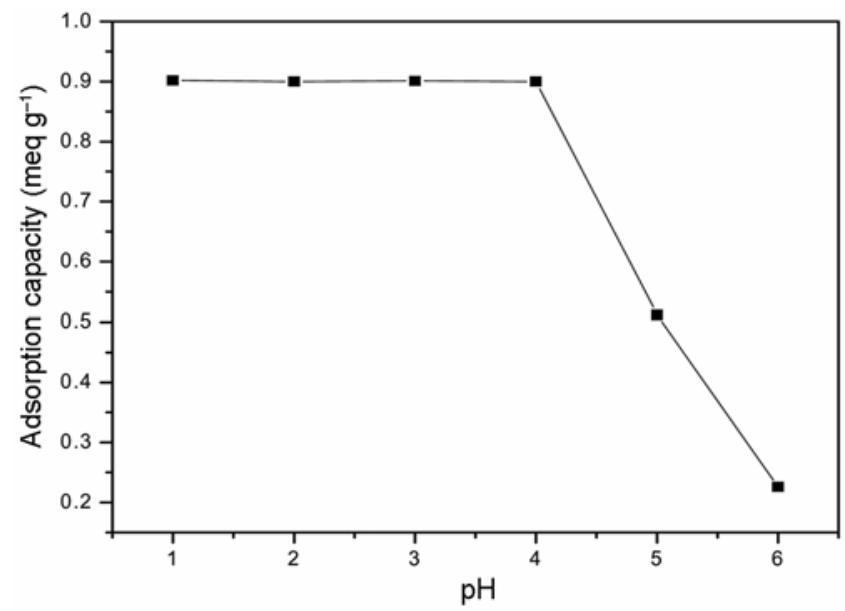

Figure 2. Effect of $\mathrm{pH}$ of permanganate solution on adsorption by HDTMA loaded clay. demonstrates that capacity of adsorption was almost the same in the acid medium and decreased with decrease in acidic strength. The sorption of permanganate was found to be maximum and constant up to $\mathrm{pH} 4 \cdot 0$, which is reduced by almost one-fifth of the quantity at $\mathrm{pH}=7$. Because, in acid media the free amino group present in HDTMA with positive charges can adsorb anions by charge neutralization. Manganese exists in acid solution in anion form $\left(\mathrm{MnO}_{4}^{-}\right)$, hence manganese can be strongly adsorbed by hexadecyltrimethylammonium.

\subsection{Breakthrough curves studies}

Experimental single solute breakthrough curves at a flow rate of $3.5 \mathrm{ml} / \mathrm{min}$ were obtained for permanganate sorption. Figure 3 shows the breakthrough data with respect to different initial surfactant loading (CEC) which was acquired by plotting the ratio of $m_{\mathrm{e}} / v$ against time, $t$, where $m_{\mathrm{e}}$ is the amount of permanganate $(\mathrm{mg})$ present in a volume, $v(\mathrm{ml})$, of the effluent collected at regular intervals of time (10 $\mathrm{min})$.

Nature of breakthrough curves of permanganate sorption at $0.5 \mathrm{CEC}$ is indicative of the small amount $\left(0.265 \mathrm{meq}^{-1}\right)$ of permanganate adsorption calculated from the total amount of permanganate adsorbed at all intervals to a gram of modified clay taken and molecular weight of the adsorbent. At 1.0 CEC loading, the amount of permanganate adsorption is maximum $\left(0.93 \mathrm{meq}^{-1}\right)$ and is comparable to the calculated CEC of the montmorillonite clay. But at 1.5 and 2.0 CEC surfactant loading the amount of permanganate adsorption is similar to that of 1.0 CEC. The adsorption capacity is saturated even at high CEC of $(>2.0)$ surfactant loading. These nature of breakthrough curves and amount of permanganate entering into the clay sheets clearly explains that

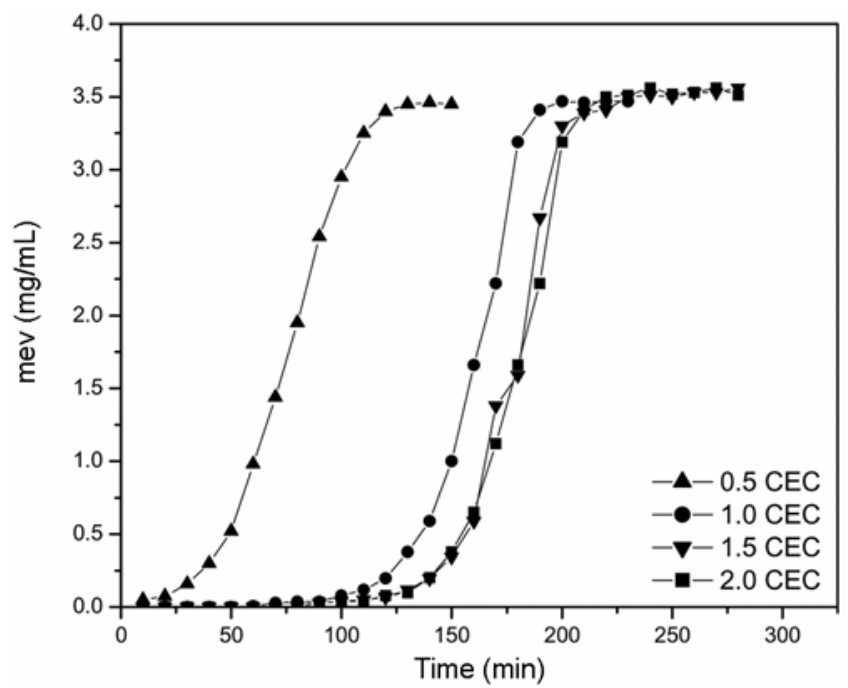

Figure 3. Breakthrough curves of permanganate adsorption at different surfactant loaded clay at $\mathrm{pH}=1 \cdot 5$. 
Table 3. Initial loading of HDTMA and amount of HDTMA adsorbed by clay.

\begin{tabular}{lcccc}
\hline & & & \multicolumn{2}{l}{ HDTMA sorbed between the montmorillonite layers } \\
\cline { 4 - 5 } $\begin{array}{l}\text { Sl. } \\
\text { no. }\end{array}$ & $\begin{array}{c}\text { HDTMA } \\
\text { loaded (CEC) }\end{array}$ & $\begin{array}{c}\text { HDTMA } \\
\text { loaded (mg) }\end{array}$ & $(\mathrm{mg})$ & $\left(\mathrm{meq} \mathrm{g}^{-1}\right)$ \\
\hline 1. & $0 \cdot 5$ & 135 & $71 \cdot 5$ & $0 \cdot 265$ \\
2. & $1 \cdot 0$ & 270 & $251 \cdot 5$ & 0.931 \\
3. & 1.5 & 405 & $250 \cdot 6$ & 0.928 \\
4. & $2 \cdot 0$ & 540 & $254 \cdot 3$ & 0.943 \\
\hline
\end{tabular}

Table 4. Amount of permanganate adsorbed for different surfactant-loaded clays.

\begin{tabular}{lcc}
\hline \multirow{2}{*}{$\begin{array}{l}\text { Initial surfactant } \\
\text { loading (CEC) }\end{array}$} & \multicolumn{2}{c}{ Amount of permanganate adsorbed } \\
\cline { 2 - 3 } & $\left(\mathrm{meq} \mathrm{g}^{-1}\right)$ & $\left(\mathrm{mg} \mathrm{g}^{-1}\right)$ \\
\hline 0.5 & $0 \cdot 265$ & 31.6 \\
$1 \cdot 0$ & 0.919 & $109 \cdot 4$ \\
1.5 & 0.930 & $110 \cdot 7$ \\
$2 \cdot 0$ & 0.936 & 111.4 \\
\hline
\end{tabular}

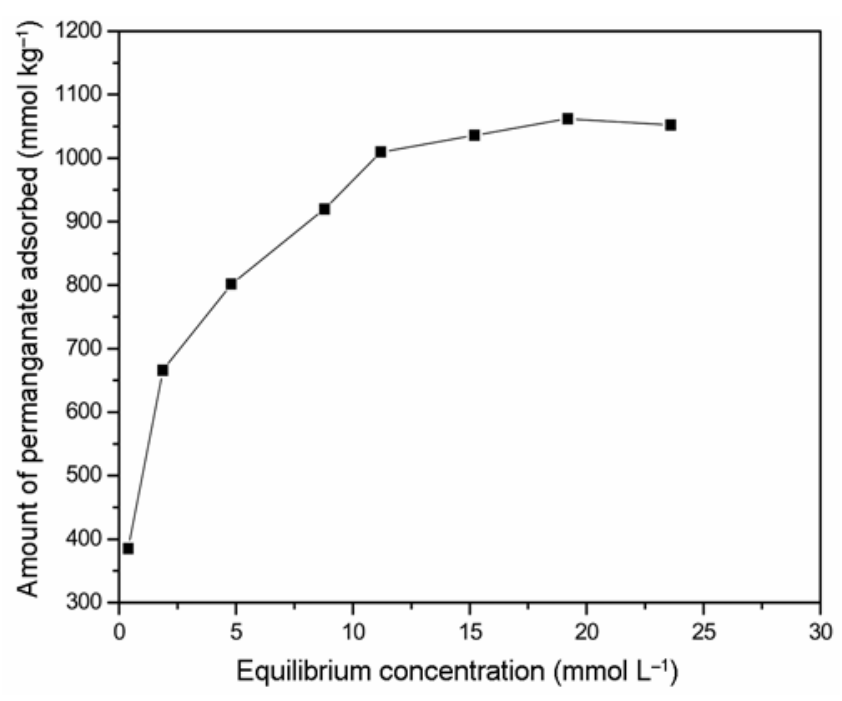

Figure 4. Sorption of isotherm for permanganate by surfactant modified clay.

1.0 CEC surfactant loaded clay is enough for the maximum sorption of permanganate from the aqueous environment. The amount of permanganate adsorbed at each $\mathrm{CEC}$ is given in table 4.

\subsection{Langmuir adsorption isotherm}

Figure 4 shows the adsorption isotherm for permanganate on modified clay at a temperature of $298 \mathrm{~K}$ and $\mathrm{pH} 1.5$. Data correlating the linear form of the Langmuir equation were used to interpret the results obtained at higher concentrations. Beyond the DKR region the relation is given by

$$
x=\frac{K_{\mathrm{L}} S_{\mathrm{m}} C}{1+K_{\mathrm{L}} C}
$$

where $x$ is the amount adsorbed on solid at equilibrium $\left(\mathrm{mmol} \mathrm{kg}{ }^{-1}\right), C$ the equilibrium solution concentration $\left(\mathrm{mmol} \mathrm{l}^{-1}\right), S_{\mathrm{m}}$ the adsorption capacity or adsorption maximum $\left(\mathrm{mmol} \mathrm{kg}^{-1}\right)$ and $K_{\mathrm{L}}$ the adsorption intensity or Langmuir coefficient $\left(\mathrm{L} \mathrm{mmol}^{-1}\right)$. Equation (1) can be rearranged in a linear form as below

$$
\frac{C}{X}=\frac{1}{K_{\mathrm{L}} S_{\mathrm{m}}}+\frac{C}{S_{\mathrm{m}}} .
$$

The data shown in table 5 are well described by the Langmuir isotherm equation when $C$ is plotted against $C / x$ according to (2) and the correlation factor for linear regression analysis is close to unity. Langmuir adsorption maximum, $S_{\mathrm{m}}$, is observed at $1115 \mathrm{mmol} \mathrm{kg}{ }^{-1}$ for permanganate on modified clay. The results obtained in $\$ 3.1$ for 1.0, 1.5 and 2.0 CEC loaded clays are 1094, 1107 and $1114 \mathrm{mmol} \mathrm{kg}^{-1}$, respectively and these results are well comparable with the Langmuir adsorption maximum.

\subsection{Thermodynamic parameters}

The amount of permanganate adsorbed by modified clay is measured in the temperature range $5-45^{\circ} \mathrm{C}$. The equilibrium partition constant, $K_{\mathrm{d}}$, is calculated as follows

$$
K_{\mathrm{d}}=\frac{x}{C_{\mathrm{e}}}
$$

where $C_{\mathrm{e}}$ is equilibrium concentration and $x$ the amount adsorbed. The following relationships have been used to evaluate the thermodynamic parameters $\Delta G^{0}, \Delta H^{0}, \Delta S^{0}$.

$$
\begin{aligned}
& \log K_{\mathrm{d}}=\frac{\Delta H^{0}}{2 \cdot 303 R T}+\frac{\Delta S^{0}}{2 \cdot 303 R}, \\
& \Delta G^{0}=-R T \ln K_{\mathrm{d}} .
\end{aligned}
$$

Figure 5 shows a plot of $\log K_{\mathrm{d}}$ vs $1 / T$ giving a straight line. The slope gives $\Delta H^{0}$ and the intercept yields the value of $\Delta S^{0}$. The change in free energy $\left(\Delta G^{0}\right)$ is computed at $25^{\circ} \mathrm{C}$ from (5) and the resultant data is given in table 6. 
The negative values of $\Delta G^{0}$ indicate that the adsorption of permanganate on surfactant clay is spontaneous. Enthalpy of adsorption of permanganate is exothermic in nature. The magnitude shows a stronger adsorbentadsorbate interaction.

\subsection{Kinetics of adsorption}

The kinetics of adsorption of permanganate by surfactant clay from aqueous solution was studied for its possible application in effluent treatment. The specific rate constant for permanganate adsorption has been interpreted in terms of the adherence of permanganate on the active sites of the adsorbent. Adsorption of permanganate from the liquid to a solid phase can be considered as a reversible reaction with equilibrium being established between

Table 5. Langmuir constants for adsorption of permanganate by surfactant modified clay.

\begin{tabular}{lc}
\hline Langmuir constants & $\begin{array}{c}\text { Adsorption of permanganate by } \\
\text { surfactant modified clay }\end{array}$ \\
\hline$S_{\mathrm{m}}\left(\mathrm{mmol} \mathrm{kg}^{-1}\right)$ & 1115 \\
$\left.K_{\mathrm{L}}(\mathrm{L} \mathrm{mmol})^{-1}\right)$ & 666 \\
$r$ (correlation factor) & $0 \cdot 994$ \\
\hline
\end{tabular}

Table 6. Thermodynamic parameters for adsorption of permanganate on surfactant modified clay.

\begin{tabular}{lc}
\hline Thermodynamic parameters & $\begin{array}{c}\text { Adsorption of permangante } \\
\text { by surfactant modified clay }\end{array}$ \\
\hline$-\Delta G^{0}\left(\mathrm{~kJ} \mathrm{~mol}^{-1}\right)$ & 3.46 \\
$-\Delta H^{0}\left(\mathrm{~kJ} \mathrm{~mol}^{-1}\right)$ & 16.65 \\
$-\Delta S^{0}\left(\mathrm{~kJ}^{-1} \mathrm{~mol}^{-1}\right)$ & $15 \cdot 5$ \\
\hline
\end{tabular}

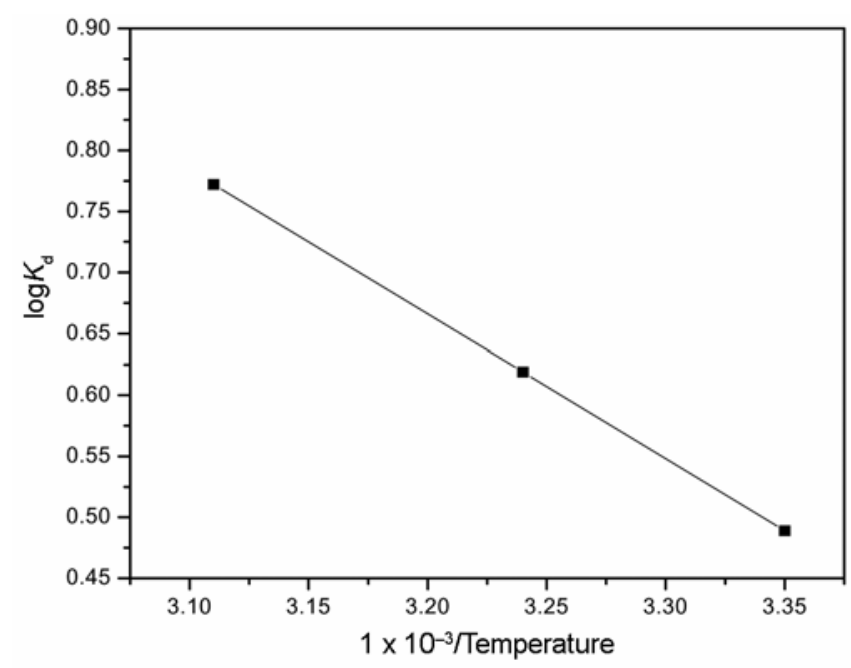

Figure 5. Plot of $\log K_{\mathrm{d}}$ vs $1 / T$ for sorption of permanganate by surfactant modified clay. the two phases. A simple first-order kinetic model is used to establish the specific rate of reaction. The first orderkinetic equation is

$$
\log \left(q_{\mathrm{o}}-q_{\mathrm{t}}\right)=\log q_{\mathrm{o}}-k_{\mathrm{r}} \frac{t}{2 \cdot 303},
$$

where $q_{\mathrm{o}}$ and $q_{\mathrm{t}}$ are concentration of permanganate in solution initially, at any time, $t$, and at equilibrium respectively, and $k$ the rate constant. Figure 6 shows the plot of $\log \left[q_{\mathrm{o}}-q_{\mathrm{t}}\right]$ vs time for permanganate. A linear relationship was observed, which indicates that the adsorption reaction can be approximated to first-order reversible kinetics.

The following equation has been used to calculate the energy of activation $\left(E_{\mathrm{a}}\right)$ for the adsorption

$$
\log \left(\frac{k_{2}}{k_{1}}\right)=\frac{E_{\mathrm{a}}\left(T_{2}-T_{1}\right)}{2 \cdot 303 R T_{1} T_{2}},
$$

where $k_{1}$ and $k_{2}$ are the rate constants at $27^{\circ} \mathrm{C}$ and $45^{\circ} \mathrm{C}$, respectively, $R$ the gas constant, $T_{1}$ and $T_{2}$ are the temperatures in kelvin, and $E_{\mathrm{a}}$ the energy of activation for the adsorption of permanganate on surface modified clay. The calculated data are given in table 7 .

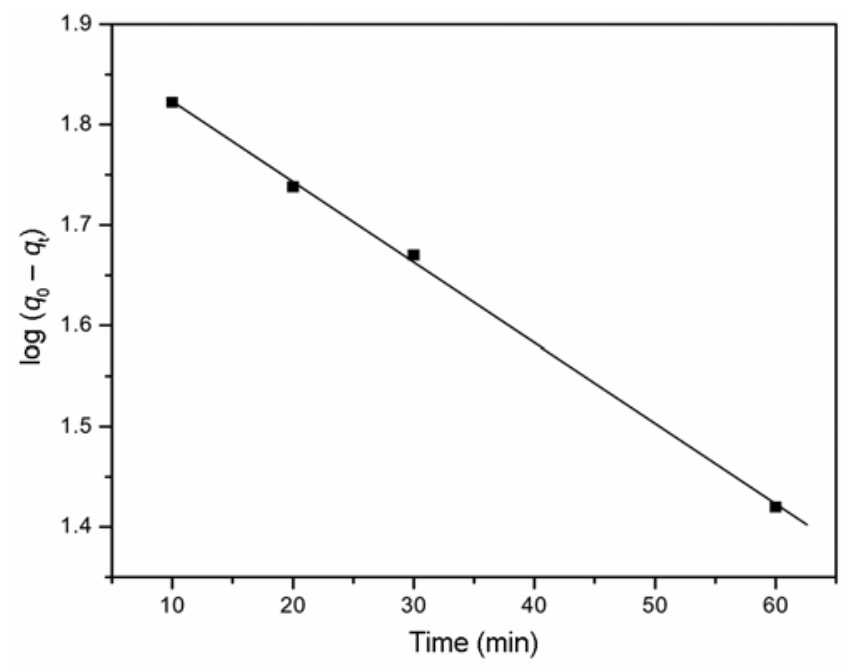

Figure 6. Plot of $\log \left(q_{\mathrm{o}}-q_{\mathrm{t}}\right)$ vs time for sorption of permanganate by surfactant modified clay.

Table 7. Specific rate constant and energy of activation for the adsorption of permanganate by surfactant modified clay.

\begin{tabular}{lc}
\hline Kinetic studies & $\begin{array}{c}\text { Adsorption of permanganate by } \\
\text { surfactant modified clay }\end{array}$ \\
\hline$k_{1}\left(\mathrm{~s}^{-1}\right)$ at $27^{\circ} \mathrm{C}$ & $4.6 \times 10^{-4}$ \\
$k_{2}\left(\mathrm{~s}^{-1}\right)$ at $45^{\circ} \mathrm{C}$ & $5 \cdot 89 \times 10^{-4}$ \\
$E_{\mathrm{a}}\left(\mathrm{kJ} \mathrm{mol}^{-1}\right)$ & $9 \cdot 70$ \\
\hline
\end{tabular}




\section{Conclusions}

Surfactant modified smectite (SMS) clays could be effectively used as specific adsorbents for removing toxic species from aqueous environment. Permanganate in the $\mathrm{pH}$ range $(\mathrm{pH}=1-4)$ can be concentrated in the interlayer of surfactant treated montmorillonite clay. Nature of breakthrough curves for permanganate adsorption on HDTMA modified montmorillonite column depends on the porosity of the adsorbent caused by the surfactant loading. The shape of the breakthrough curves obtained varied with the amount of surfactant loading. The shapes clearly indicate that 1.0 CEC surfactant loaded clay is enough for complete adsorption of permanganate which is equal to the cation exchange capacity of the raw clay. The amount of surfactant loaded determines the entry of ions thus suggesting a possibility of a novel method of separation based on exclusion by the variation of interlayer swelling brought about by surfactant loading. Calculation of thermodynamic parameters shows that the adsorption of permanganate is spontaneous and follows the first order kinetics.

\section{References}

ATSDR 2000 Toxicological profile for manganese. U.S. Department of Health and Human Services, Public Health
Service, Agency for Toxic Substances and Disease Registry, Atlanta, GA

Bown H J M (ed) 1979 Environmental chemistry of elements (London: Academic Press)

Boyd C E (ed) 1990 Water quality in ponds for aquaculture (Alabama: Birminglum Publishing Co) p. 482

Donavan S M, Monaco M H and Clegg M S 1999 Nerotox. 20 213

Griffin A E 1960 J. Am. Water Works Assoc. 521326

IPCS 1999 Manganese and its compounds, Concise International Chemical Assessment Document 12, International Programme on Chemical Safety, WHO

Keen C L, Ensunsa J L and Clegg M S $2000 \mathrm{~J}$. Biol. Syst. 3789

Krishna B S, Mahadevaiah N, Murty D S R and Jai Prakash B S 2004 J. Colloid Inter. Sci. 271270

Lin S H and Juang R S 2002 J. Hazard. Mater. 92315

Mahadevaiah N, Venkataramani B and Jai Prakash B S 2007 Chem. Mater. 194606

Mahadevaiah N, Venkataramani B and Jai Prakash B S 2008 Ind. Eng. Chem. Res. 471755

Patchett P J and Tatsumoto M 1975 Contrib. Mineral. Petrol. 75263

Sandell E B 1958 Colorimetric determination of traces of metals (New York: Interscience Publ)

Tucker C S and Boyd C E 1977 T. Am. Fish. Soc. 106481

Zhang K, Li C, He J and Liu R 1997 J. West China Med. Sci. 28 344 